5.

Derecho constitucional 

Revista de Derecho

de la Pontificia Universidad Católica de Valparaíso

XXXIV (Valparaíso, Chile, $1^{\text {er }}$ Semestre de 2010)

[pp. $523-541]$

\title{
EL NEOCONSTITUCIONALISMO Y EL RECURSO A LOS \\ VALORES EN LA JURISPRUDENCIA DEL TRIBUNAL \\ CONSTITUCiOnAl CHILENO*
}

["Neoconstitucionalism and Appeal to Values in the Jurisprudence of the Chilean Constitutional Court"]

\author{
Manuel A. NúNEzZ Poblete** \\ Universidad Católica del Norte
}

\section{RESUMEN}

El presente artículo describe las principales tendencias del llamado "neoconstitucionalismo" por la doctrina predominante. Especial atención se dispensa al uso de los valores en la jurisprudencia constitucional, como asimismo a sus contradicciones y consecuencias problemáticas frente al concepto liberal de la constitución. El autor pretende demostrar que, en ciertos aspectos, el neoconstitucionalismo puede no tener nada de nuevo ni de constitucional.

Palabras Clave: Neoconstitucionalismo - valores constitucionales - jurisprudencia constitucional.

\section{ABSTRACT}

This paper describes the main patterns of the so called "new constitutionalism" in the current doctrine. The use of values in constitutional adjudication deserves special attention, as well as its contradictions and problematic consequences before the concept of constitution. It is argued that, in some extent, the new-constitutionalism may not be new neither constitutional.

KEYWORDS: New constitutionalism - constitutional values - constitutional jurisprudence.

* El presente trabajo forma parte del Proyecto de investigación No 1090424, patrocinado por el Fondo Nacional de Desarrollo Científico y Tecnológico (FONDECYT) y del cual el autor es coinvestigador. El autor agradece la asistencia en las labores de investigación de las Srtas. Fernanda Pérez (Escuela de Derecho, Universidad Católica del Norte) y Cristina Meza (Escuela de Derecho, Universidad de Antofagasta).

** Doctor en Derecho, Profesor de Derecho constitucional de la Escuela de Derecho de la Universidad Católica del Norte. Dirección postal: Avenida Angamos 0610, Antofagasta. Correo electrónico: manunez@ucn.cl 


\section{INTRODUCCIÓN Y PRECISIONES CONCEPTUALES}

En los últimos años ha circulado con especial éxito en la literatura hispanoparlante el adjetivo "neoconstitucional" para identificar una serie de fenómenos que se advierten en la teoría y prácticas constitucionales de la segunda mitad del siglo XX y principios del siglo XXI. La presente investigación tiene por objeto, previa identificación de los rasgos comunes atribuidos a dicho fenómeno, identificar los modos más sensibles de recepción de dicha corriente en la jurisprudencia del Tribunal Constitucional chileno con el objeto de contrastar sus proyecciones con el sentido liberal del estado constitucional y democrático de derecho. Para ello, esta investigación asume como premisa un contenido mínimo de lo constitucional y de lo democrático, entendiendo como parte de este concepto el sentido libertario o protector de la libertad que se espera en toda Constitución como instrumento de limitación y orientación del poder. Para ello, se despejarán previamente los sentidos en que puede hablarse de neoconstitucionalismo, se identificará en el discurso argumental sobre los valores una de las principales manifestaciones de dicha tendencia en la jurisprudencia del Tribunal y se contrastará su contenido con aquello que de "nuevo" y de "constitucional" habría de tener lo neoconstitucional.

En la literatura constitucional contemporánea, especialmente la europea continental y la latinoamericana, ha adquirido carta de ciudadanía el término "neoconstitucionalismo". De acuerdo con la abundante literatura, este término -aparentemente adjetivo del constitucionalismo- parece estar preñado de una diversidad de significaciones ${ }^{1}$. Esta pluralidad de significaciones comprende desde el nombre que cierta crítica politológica ha hecho al modelo jurídico que sustenta al capitalismo ${ }^{2}$ hasta el calificativo general con que se han etiquetado los problemas que han enfrentado los estados constitucionales en los últimos cincuenta años. Esta problemática es tan pluriforme, y los diagnósticos y respuestas tan divergentes que hay

${ }^{1}$ Véanse, entre otros, CARBOnELl, Miguel, El neoconstitucionalismo en su laberinto, en El MISMO (coordinador), Teoría del neoconstitucionalismo. Ensayos escogidos (Madrid, Trotta, 2007), pp. 9-14; ComanducCI, Paolo, Formas de (neo)constitucionalismo: un análisis metateórico, en CARBOnell, Miguel (editor), Neoconstitucionalismo(s) (Madrid, Trotta, 2003), pp. 75 ss.; Durán, Augusto, En torno al neoconstitucionalismo, en Arancibia, Jaime - MarTínez, José Ignacio (coordinadores), La primacía de la persona. Estudios en homenaje al Profesor Eduardo Soto Kloss (Santiago de Chile, LegalPublishing - Abeledo Perrot, 2009), pp. 390 ss.; Pozzolo, Susana, Neocostituzionalismo: breve nota sulla fortuna di una parola, en Materiali per una storia della cultura giuridica, 38 (2008) 2, pp. 405-417.

${ }^{2}$ GILL, Stephen. The constitution of global capitalism, en <http://www.theglobalsite.ac.uk/press/010gill.pdf> (2002) [fecha de consulta: 3 de enero de 2010]. 
quien se ha atrevido a sostener que, más que una teoría sistemática, el neoconstitucionalismo es una suerte de "atmósfera cultural"3.

El neoconstitucionalismo o nuevo constitucionalismo, más que designar una doctrina se identifica con diversas evidencias. Entre las manifestaciones más difundidas en la ciencia jurídica contemporánea pueden identificarse las siguientes: el crecimiento de las atribuciones de la judicatura constitucional, la constitucionalización del derecho, la difusión de la concepción axiológica de los derechos constitucionales, la progresiva consolidación de ciertas metodologías de resolución de conflictos (tales como la ponderación) o de ciertos principios de escrutinio judicial de la actividad pública (tales como el principio de subsidiariedad) que aumentan la incidencia de los jueces en el ámbito público o privado, la renovación del concepto de principios del Derecho, la crisis de las constituciones nacionales frente a la globalización, y la apertura de las constituciones y las magistraturas nacionales frente al Derecho internacional y al comparado. A esta versión del neoconstitucionalismo, que ha sido la más difundida en Chile y Latinoamérica, hay que añadir los aportes de la doctrina europea para sistematizar el análisis jurídico de la Unión Europea. Como se sabe, el desarrollo político y jurídico de esta última unión de estados ha obligado a repensar el discurso constitucional de matriz estatal y a construir una teoría constitucional adecuada para una nueva forma de comunidad política. Con esta última idea pueden identificarse los estudios sobre el neoconstitucionalismo europeo ${ }^{4}$, el discurso metaconstitucional ${ }^{5}$, las teorías sobre el pluralismo constitucional ${ }^{6}$, el constitucionalismo de varios niveles ${ }^{7}$, el constitucionalismo postnacional ${ }^{8}$ y el constitucionalismo postmoderno ${ }^{9}$.

De todas las proyecciones mencionadas, la que interesa subrayar a los

${ }^{3}$ SChiavello, Aldo, Neocostituzionalismo o neocostituzionalismi, en Diritto e questione pubbliche, 3 (2003), p. 37.

${ }^{4}$ WeILER, Joseph, European Neo-constitutionalism, en Search of Foundations for the European Constitutional Order, en BELLAMY - CASTIGLIONE (editores) Constitutionalism in Transformation: European and Theoretical Perspectives (Oxford, Blackwell, 1996) pp. 105-121.

${ }^{5}$ WaLKer, Neil, Flexibility within a Metaconstitutional Frame: Reflections of the future of legal authority in Europe, en Jean Monnet Working Paper, 12 (1999).

${ }^{6}$ WaLKer, Neil, The Idea of Constitutional Pluralism, en Modern Law Review, 65 (2002), pp. 317-359.

${ }^{7}$ Pernice, Ingolf, Multilevel Constitutionalism in the European Union, en European Law Review, 27 (2002), pp. 511-529.

${ }^{8}$ SHaw, Jo, Postnational constitutionalism in the European Union, en Journal of European Public Policy, 6 (1999) 4, pp. 579-597.

${ }^{9}$ NúNEZ, Manuel, Una introducción al constitucionalismo postmoderno y al pluralismo constitucional, en Revista Chilena de Derecho, 31 (2004) 1, pp. 115-136. 
efectos de la presente investigación es aquella que consiste en el predominio del enfoque axiológico sobre la constitución en general y sobre los derechos fundamentales en particular. Para buena parte de la doctrina especializada, la penetración del concepto de valores en el discurso constitucional representa uno de los rasgos más llamativos del llamado neoconstitucionalismo. Este discurso se caracteriza por trasladar un concepto que era más propio de la ética al campo de la argumentación judicial y tiene su origen en la doctrina y en la praxis constitucional alemana de la postguerra. Esta visión de los derechos fundamentales se remonta a las teorías de Rudolf Smend quien en 1928 formuló la tesis de que la Constitución es la expresión de un sistema concreto de valores y de un sistema cultural ${ }^{10}$. Esta tesis tuvo bastante éxito en la doctrina y obtuvo carta de ciudadanía el año 1958 con la sentencia $L \ddot{u} t h^{11}$ del Tribunal Constitucional alemán, donde dicho Tribunal estimó la Ley Fundamental como "un orden objetivo de valores" o un "sistema de valores" que fortalece el poder de los derechos fundamentales. Posteriormente, la idea alemana circuló con particular fluidez hacia otros países especialmente receptivos a la ciencia jurídica alemana ${ }^{12}$, como por ejemplo España ${ }^{13} \mathrm{o} \operatorname{Italia}^{14} \mathrm{y}$, desde allí, Latinoamérica.

\section{LA RECEPCIÓN DEL MODELO DE LOS VALORES EN LA JURISPRUdenCIA DEL TRIBUnAL CONSTITUCIONAL CHILENO}

En otro lugar he demostrado que la jurisprudencia del Tribunal Constitucional fue tempranamente influenciada por la literatura científica francesa e italiana antes que por la ciencia alemana. La excepción a esta tendencia la representa, precisamente, el recurso a los valores como parte del discurso constitucional. En efecto, es en una sentencia de 1973, relativa al proyecto de ley sobre áreas de la economía (STC rol No 15, 30 de mayo de 1973), donde aparece una de las primeras referencias hacia el

${ }^{10}$ SmEnd, Rudolf, Constitución y Derecho Constitucional (traducción de J. M. Beneyto, Madrid, Centro de Estudios Constitucionales, 1985), pp. 133 ss.

${ }^{11}$ Sentencia de 15 de enero de 1958, BVerfGE., 7, pp. 198 ss., especialmente p. 204.

${ }^{12}$ Кокотт, Juliane, From Reception and Transplantation to Convergence of Constitutionals Models in the Age of Globalisation with Special Reference to the German Basic Law, en StARCK, C. (editor), Constitutionalism, Universalism and Democracy. A comparative analysis (Baden Baden, Nomos, 1999), pp. 92-97.

${ }^{13}$ Parejo, Luciano, Constitución y valores del ordenamiento (Madrid, Centro de Estudios Ramón Areces, 1990); ÉL MISMO, "Valores supremos", en Enciclopedia Jurídica Básica (Madrid, Civitas, 1995), IV, pp. 6811 ss.

${ }^{14}$ RugGeri, Antonio, Balances" entre los valores constitucionales y teoría de las fuentes, en Teoría y Realidad Constitucional, 12-13 (2004), p. 157. 
contenido y escala de los valores constitucionales como parte de los límites inmanentes a la reforma constitucional ${ }^{15}$. Lo temprana de esta referencia hace pensar que, en cierta medida, la creación del Tribunal Constitucional y la penetración de las concepciones axiológicas de la Constitución son dos fenómenos contemporáneos en Chile. En lo que se refiere al desarrollo posterior de este concepto es fácil advertir dos etapas, coincidentes con el desarrollo de casi toda la jurisprudencia del Tribunal. La primera de ellas va desde el restablecimiento del Tribunal Constitucional hasta la entrada en vigor de la reforma del 2005, mientras que la segunda va desde esta última fecha hasta nuestros días. La primera etapa se caracteriza por el recurso moderado al argumento de los valores, método discursivo que tras la interrupción de 1973 se inaugura durante la segunda mitad de la década de los ochenta ${ }^{16}$ y se desarrolla notablemente durante la última etapa. En este último período se advierte un uso más frecuente de este lenguaje, azuzado por la sensibilidad de los problemas llevados ante el Tribunal y por la nueva estructura del recurso de inaplicabilidad, encontrándose algunos casos donde el término es utilizado con especial insistencia. Las sentencias sobre la píldora del día después (especialmente la segunda) ${ }^{17}$, sobre el caso Isapre ${ }^{18}$, sobre la reparación del daño moral en el caso del artículo 2331 CC. ("Valdés Correa" y "Ominami Pascual") 19 o sobre la investigación de la paternidad ${ }^{20}$ son paradigmáticas en ese sentido.

De todos los modos posibles de entender el concepto de valor ${ }^{21}$ interesa destacar en esta investigación aquellos usos que inciden en aquello que de nuevo y de constitucional que puede tener, valga la redundancia, lo

${ }^{15}$ Voto del Ministro Veloso, II, A.

${ }^{16}$ Valenzuela, Eugenio, Criterios de hermenéutica constitucional aplicados por el Tribunal Constitucional. Contribución del Tribunal a la institucionalización democrática, en Cuadernos del Tribunal Constitucional, 31 (Santiago de Chile, 2006), pp. 18 ss.

${ }^{17}$ STC rol No 740 , de 18 de abril de 2008.

${ }^{18}$ SS.TC roles $\mathrm{N}^{\text {os }} 967$, de 26 de junio de 2008), No 1218, de 7 de julio de 2009), No 1287, de 8 de septiembre de 2009, y N N $^{\circ} 1273$, de 20 de abril de 2010, todas sobre inaplicabilidades acogidas.

${ }^{19}$ SS.TC roles No 943, de 10 de junio de 2008 y No 1185 , de 16 de abril de 2009.

${ }^{20}$ STC rol No 1340, de 29 de septiembre de 2009.

${ }^{21}$ Véase: Pérez MuÑoz, Fernanda, El recurso a los valores en la jurisprudencia del Tribunal Constitucional chileno (2006-2009) (Memoria de Licenciatura, Prof. guía M. Núñez P., Escuela de Derecho de la Universidad Católica del Norte, Antofagasta, 2010), pp. 9 ss.; y MEZA ZÚÑIGA, Cristina, El recurso a los valores en la jurisprudencia del Tribunal Constitucional chileno (1970-2006) (Memoria de Licenciatura, Prof. guía M. Núñez P., Facultad de Ciencias Jurídicas de la Universidad de Antofagasta, Antofagasta, 2010), pp. 11 ss. 
neoconstitucional. De allí que entre esos modos haya parecido conveniente destacar tres: la referencia a los valores como sustrato de la identidad constitucional nacional, como criterios rectores de la interpretación constitucional y de la actuación de las personas públicas y privadas.

\section{Valores como sustrato de la identidad constitucional nacional y limite} al Derecho internacional.

En alguna sentencia dictada durante la década de los ochenta el Tribunal pudo elaborar someramente la categoría de "valores esenciales de la tradición chilena" a que se refiere el artículo 22 C.Pol. ${ }^{22}$, entendidos como "esencia de la chilenidad". Este tipo de valores, en la misma sentencia, son identificados como un criterio de limitación al proceso de interpretación de las normas internacionales ${ }^{23}$. Este embrionario modo de entender la identidad constitucional, muy cercano a la idea de nacionalismo, poco tiene que ver con las modernas aplicaciones de la "Verfassungsidentität" o "constitutional identity" que se advierten con especial reiteración en la práctica constitucional europea. Vinculado a la idea de "chilenidad", la concepción de la identidad se inserta en la tradicional reticencia que muestra el Tribunal Constitucional hacia la apertura de la Constitución frente a las normas internacionales. En este sentido parece todavía prematuro hablar de las bases para una jurisprudencia de contra-límites (en la terminología que puso de moda la doctrina y jurisprudencia italianas), tendencia muy propia de ciertas versiones del constitucionalismo postmoderno.

\section{Valores como criterios rectores de la interpretación constitucional.}

Probablemente esta sea la categoría más sustanciosa de aplicación del concepto de valores en la jurisprudencia constitucional. Esta última suele recurrir a una trilogía bastante conocida en la teoría constitucional y sobre la cual la doctrina, desde las perspectivas más variadas, ha prodigado numerosos estudios. Se trata de las normas, los principios y los valores constitucionales. Al hacer explícita su metodología de interpretación, el Tribunal suele utilizar estos tres conceptos, conjuntamente o separadamente, para decir que ellos orientan la interpretación de la Constitución

${ }^{22}$ STC rol No 46, de 21 de diciembre de 1987, consid. $45^{\circ}$.

${ }^{23}$ STC rol No 46, de 25 de diciembre de 1987, consid. 29०: "Que a mayor abundamiento, $y$ sin pretender agotar el tema, atendido lo expuesto en los dos considerandos precedentes, el artículo $8^{\circ}$ de la Constitución cuya finalidad, según se expresa en la historia de su establecimiento, es 'proteger la democracia' y 'preservar los valores básicos en que se funda la institucionalidad' no vulnera normas internacionales, ya que éstas no deben interpretarse en el sentido de conferir derechos a personas o grupos de personas para realizar actos tendientes a destruir los valores aludidos". 
y de las leyes. En la medida en que la hermenéutica se orienta por estos valores, es que la doctrina nacional de los profesores ${ }^{24} \mathrm{y}$ de los profesoresjueces $^{25}$ se refiere a la interpretación "axiológica" o "axiológica-finalista" de la Constitución.

En una visión global de la práctica es posible discernir, en primer lugar, aquellos casos en que la calificación de un mismo objeto oscila entre los principios o los valores (como acontece con la supremacía constitucional) ${ }^{26} \mathrm{o}$ entre los valores y las normas (como sucede con los derechos en particular) ${ }^{27}$. Esta variabilidad, que se observa especialmente durante el período inaugurado con la vigencia de las reformas del 2005, no parece obedecer a un criterio orgánico, por lo que sólo cabría considerarla como una evidencia más (anecdótica, quizá) de la notable difusión de un lenguaje que ha encontrado finos adeptos al interior de nuestro Tribunal Constitucional y que no siempre corresponde a un proceso decantado de inteligencia y aplicación.

En segundo lugar, y siempre dentro de esta visión global, es posible identificar un número bastante importante de sentencias donde el recurso a los valores viene acompañado de la referencia a las normas y a los principios constitucionales. En materia de interpretación esta tendencia parece surgir por primera vez en el fallo "Almeyda" sobre aplicación del antiguo artículo

${ }^{24}$ Nogueira, Humberto, Lineamientos de interpretación constitucional (Santiago de Chile, Librotecnia, 2006), pp. 96 ss. Vivanco, Ángela, Curso de Derecho constitucional. Bases conceptuales y doctrinarias del Derecho constitucional (Santiago de Chile, Ediciones Pontificia Universidad Católica de Chile, 2001), Tomo I, p. 415

${ }^{25}$ Valenzuela, Eugenio, Criterios de hermenéutica constitucional aplicados por el Tribunal Constitucional. Contribución del Tribunal a la institucionalización de la democrática, en Cuadernos del Tribunal Constitucional, 31 (Santiago de Chile, 2006), pp. 18 ss.; CEA, José Luis, La interpretación axiológica de la Constitución, en VV. AA., Interpretación, integración y razonamiento jurídicos (Santiago de Chile, Editorial Jurídica de Chile, 1992), pp. 89 ss.; CEA, José Luis, Escritos de justicia constitucional, en Cuadernos del Tribunal Constitucional, 35 (Santiago de Chile, 2007), p. 163.

${ }^{26}$ Entre los fallos que califican a la supremacía como un valor, véanse: SS. TC roles No 1218 , de 7 de julio de 2009 , consid. $57^{\circ}$; No 976, de 26 de junio de 2008, consid. 57\%; y No 792, de 3 de enero de 2008 , consid. $5^{\circ}$. Para la consideración como principios, véanse: SS.TC roles No 176, de 22 de noviembre de 1993, consid. $23^{\circ}$; No 190 , de 7 de diciembre de 1994 , consid. $14^{\circ}$; y No 207, de 10 de febrero de 1995 , consid. $20^{\circ}$.

${ }^{27}$ Varios de los derechos contenidos en las normas del artículo 19 son considerados como valores. Así por ejemplo la intimidad (STC rol No 1.246, 1 de diciembre de 2009, consid. $5^{\circ}$ ); la intangibilidad del contenido esencial (STC rol No 1337, de 20 de agosto de 2009, voto Ministro Colombo, $14^{\circ}$ ); el acceso al proceso (STC rol No 1247 , de 14 de julio de 2009 , consid. $5^{\circ}$ ); y el derecho a la protección de la salud (STC rol No 804, de 28 de diciembre de 2007, consid. 32º). 
8 C.Pol. (STC rol No 46, 21 de diciembre de 1987). En esta sentencia se lee "[q]ue de lo expuesto en los considerandos anteriores se infiere con nitidez que el ordenamiento institucional estructurado por la Constitución de 1980 descansa sobre ciertos principios y valores básicos, entre los cuales, cabe señalar, por su íntima vinculación con el problema que se analiza, los siguientes: la libertad del hombre, que los derechos fundamentales de la persona humana son anteriores y superiores al Estado y a la Constitución, razón por la cual ésta no los crea sino que los 'reconoce y asegura'; que el Estado en cumplimiento de su finalidad propia, cual es promover el bien común, debe darles segura y eficaz protección" (consid. 19). A partir de esta sentencia (que será después tomada y transformada por los fallos sobre ISAPRES) el Tribunal insistirá en que su función no consiste solo en guardar las normas constitucionales, sino que también consiste en vigilar, dentro de sus competencias, que todas las autoridades públicas sometan su acción a las normas, principios y valores constitucionales ${ }^{28}$.

Para el Tribunal Constitucional los valores "presiden" el ordenamiento jurídico ${ }^{29}$ y su interpretación, en el sentido que ellos conducen a descartar las interpretaciones "fáciles" ${ }^{30}$, las "contradicciones aparentes" ${ }^{31}$ y las interpretaciones opuestas a dichos valores ${ }^{32}$. Indagando por la sustancia que diferencia a los valores de las normas y principios, el Tribunal parece compartir con la doctrina el carácter fundante que tendrían los primeros frente a las normas. En una sentencia de 2008, recaída en un proceso que tuvo mucha notoriedad en la prensa, el Tribunal explicó así la relación entre las normas y los valores: "[q] ue las disposiciones contenidas en los artículos 1 y 4 de la Ley Fundamental se reconocen, a la vez, como normas jurídicas y como valores fundamentales del ordenamiento, que deben informar y guiar el actuar de todos los órganos del Estado. En tanto valores fundamentales, abstractos y generales, se concretan en otras normas especificas, tanto constitucionales como legales, las cuales, en tanto normas jurídica, deben ir

${ }^{28}$ STC rol No 591, de 11 de enero de 2007, consid. $8^{\circ}$ : "La jurisdicción constitucional debe asegurar que, efectivamente, todas las autoridades públicas sujeten sus actos (aqui quedan comprendidos, entre otros, las leyes, las sentencias y los actos administrativos) a las normas, valores y principios constitucionales, de modo que cada una de las funciones estatales se desarrolle dentro de un ámbito correcto y de legitimo ejercicio de la función constitucional que les compete".

${ }^{29}$ STC rol No 825, de 6 de enero de 2008, voto de los ministros Vodanovic y Fernández Baeza, apdo. 4º. En el mismo sentido, véase la STC rol No 829, de 6 de marzo de 2008.

${ }^{30}$ SS.TC rol No 325 , de 26 de junio de 2001, consid. $11^{\circ}$; y rol No 591, de 11 de enero de 2007 , consid. $5^{\circ}$.

${ }^{31}$ STC rol No 549 , de 30 de marzo de 2007 , consid. $10^{\circ}$.

${ }^{32}$ STC rol No 1185 , de 16 de abril de 2009 , consid. $13^{\circ}$. 
acompañadas de medidas y remedios procesales que las garanticen. Dentro de dichas normas especificas se encuentran los derechos fundamentales invocados por la requirente, los cuales, al no verse infringidos, no puede considerarse que se encuentre lesionado su contexto valórico general, dentro del cual se incluyen los artículos 1 y 4 de la Constitución" $"$.

3. Valores como criterios rectores de la actuación de las personas y todos los poderes públicos.

En el primer fallo sobre el caso de la píldora del día después el Tribunal identificó en los valores constitucionales una suerte de carta de navegación para los poderes públicos, puesto que la realización de estos valores representa, según una frase atribuida a Dilthey, "el proyecto máximo, el supremo objetivo de la comunidad nacional" 34 . De este proyecto y su "finalidad humanista" 35 participarían, en concepto del Tribunal, tanto los órganos del Estado como los particulares.

En la primera sentencia recaída sobre el artículo 2331 CC., el Tribunal hace propio el concepto de fuerza normativa de la Constitución y el efecto irradiante de los valores constitucionales: "[q] ue, como ya se ha señalado, el contenido del artículo 19 de la Carta Fundamental, conjuntamente con sus artículos $1^{\circ}, 4^{\circ}$ y $5^{\circ}$, inciso segundo, de la misma, configuran principios y valores básicos de fuerza obligatoria que impregnan toda la Constitución de una finalidad humanista que se irradia en la primacia que asignan sus disposiciones a la persona humana, a su dignidad y libertad natural, en el respeto, promoción y protección a los derechos esenciales que emanan de la naturaleza humana, que se imponen como limitación del ejercicio de la soberanía y como deber de los órganos del Estado"36. Luego señala "[q] ue estos principios y valores, como ya se recordó -y lo hace manifiesto el inciso segundo del artículo $\sigma^{\circ}$ de la Constitución, que precisa que sus preceptos obligan no sólo a los titulares o integrantes de los órganos del Estado sino a toda persona, institución o grupo-, no configuran meras declaraciones programáticas sino que constituyen mandatos expresos para gobernantes y gobernados, debiendo presidir la labor del intérprete constitucional, en cuanto normas rectoras y

${ }^{33}$ STC rol No 986 , de 30 de enero de 2008 , consid. $30^{\circ}$. El fallo incidía en la causa seguida contra el "homicida del bate de baseball".

${ }^{34}$ STC rol No 591, de 11 de enero de 2007, consid. $30^{\circ}$.

${ }^{35}$ SS.TC roles $\mathrm{N}^{\circ} 943$, de 10 de junio de 2008 , consid. $30^{\circ}$; y $\mathrm{N}^{\circ} 1185$, de 16 de abril de 2009 , consid. $11^{\circ}$.

${ }^{36} \mathrm{STC}$ rol No 943 , de 10 de junio de 2008 , consid. $30^{\circ}$. Véase en igual sentido la STC rol No 1185 , de 16 de abril de 2009. 
vitales que coadyuvan a desentrañar el verdadero sentido y espiritu del resto de las disposiciones de la Constitución" ${ }^{37}$.

De acuerdo con la doctrina desarrollada por el Tribunal, el Estado -particularmente el legislador- debe tener especialmente en cuenta que los valores constitucionales pueden justificar la limitación de los intereses individuales: "una interpretación finalista, como la que tradicionalmente ha propiciado esta Magistratura Constitucional, debe llevar a la conclusión de que la primacía de la persona, unida al principio de servicialidad del Estado, tal y como se consignan en el artículo 1, inciso $4^{\circ}$ C.Pol., permite que el ordenamiento jurídico reconozca y regule la protección de intereses individuales legítimos que resulten acordes con los valores y principios constitucionales. Naturalmente, cuando así no ocurre, el propio ordenamiento jurídico desplaza la protección del interés particular dando primacía a valores o principios inherentes a la misma vida en sociedad. Este es el caso de la probidad administrativa" 38 .

Por lo que se refiere a los particulares, en una sentencia reciente sobre el proyecto de ley sobre información, orientación y prestaciones en materia de regulación de la fertilidad (hoy la Ley No 20.418, D. Of. de 28 de enero de 2010) se revisó la constitucionalidad del precepto que establece la obligación de incluir un programa de educación sexual en la enseñanza media. Este programa "según sus principios y valores", incluirá "contenidos que propendan a una sexualidad responsable e informe de manera completa sobre los diversos métodos anticonceptivos existentes y autorizados, de acuerdo al proyecto educativo, convicciones y creencias que adopte e imparta cada establecimiento educacional en conjunto con los centros de padres y apoderados". Sobre esta norma la Ministra Peña, en su voto concurrente, sugirió "que 'los principios y valores', así como 'las convicciones y creencias que imparta cada establecimiento educacional en conjunto con los centros de padres y apoderados' en las materias que esa norma indica, deben enmarcarse plenamente dentro del respeto a los derechos fundamentales que la Constitución Politica, así como los tratados internacionales ratificados por Chile y vigentes reconocen y consagran, especialmente, en lo que respecta al derecho a la vida asegurado a toda persona”.

El voto concurrente recién transcrito no representa una visión aislada de la funcionalidad de los valores, pues ya es doctrina del Tribunal el que los valores constitucionales limiten la esfera individual y, con ello, la

${ }^{37}$ STC rol No 943 , de 10 de junio de 2008 , consid. $31^{\circ}$. En el mismo sentido STC rol No 976 , de 26 de junio de 2008 , consid. $35^{\circ}$.

${ }^{38}$ STC rol No 634 , de 9 de agosto de 2007 , consid. $30^{\circ}$. 
libertad para definir otras preferencias. Queda abierta así, la tensión entre los valores y la libertad.

\section{Apreciación CRÍTICA. ¿QUÉ TAN “NEO” Y “CONSTITUCIONAL” ES LA TEORÍA Y LA PRAXIS NEOCONSTITUCIONAL NACIONAL?}

En la academia muchas veces se dan por descontados ciertos contenidos sustantivos a partir de la difusión de ciertas etiquetas, aunque lo propio de la reflexión sea precisamente la indagación por los contenidos antes que por los nombres. Por eso no debe llamar la atención que los economistas se pregunten acerca de qué y cuánto hay de nuevo tras el llamado neoliberalismo y que, del mismo modo, los juristas se cuestionen sobre lo que de "jurisdicción" tenga la llamada jurisdicción constitucional, lo que de "procesal" tengan los estudios sobre el Derecho procesal constitucional o, en lo que en este ensayo importa, lo de "nuevo" y lo de "constitucional" que pueda tener lo neoconstitucional.

Por de pronto cabe señalar que como neologismo el "neo"-constitucionalismo no es tan nuevo. El término lo encuentro en los Principios generales del Derecho constitucional de Gabriel Amunátegui editado en 1953. Este escrito radica los orígenes del fenómeno llamado neoconstitucionalismo a principios del siglo $\mathrm{XX}^{39}$, al igual que Verdugo y García cuyo Manual de Derecho político (editado por primera vez en 1979, explicaba que el neoconstitucionalismo designaba "las tendencias doctrinarias que (...) más que rectificar en su esencia los principios y técnicas del constitucionalismo clásico, vienen a complementar y a dar adecuación histórica a los mismos" 40 . Lo nuevo, entonces, no debe buscarse en la etiqueta sino en parte de los contenidos que usualmente se consideran parte del fenómeno neoconstitucional. En este sentido, puede decirse que el neoconstitucionalismo recién comienza a advertirse en las postrimerías de la Constitución de 1925 (la disidencia del Ministro Veloso es una evidencia de ello) consolidándose con la vigencia de la Constitución de 1980 a partir de la formación del método axiológico de interpretación de la Constitución.

Con todo, la tendencia hacia el neoconstitucionalismo en la jurisprudencia del Tribunal constitucional también convive con diversas contradicciones que deslucen su presunta novedad. Entre estas destaca en primer lugar la convivencia de lo "neo" con los más "vetero" del razonamiento ilustrado. Por señalar un ejemplo llamativo: poco o nada de "neo" tiene la

${ }^{39}$ AmunÁtegui, Gabriel, Principios generales del Derecho constitucional (Santiago de Chile, Editorial Jurídica de Chile, 1953), pp. 59 ss.

${ }^{40}$ Verdugo, Mario - García, Ana María, Manual de Derecho político. Instituciones políticas (Santiago de Chile, Editorial Jurídica de Chile, 1996), p. 273. 
presunción de "sabiduría" 41 del constituyente que nuestro Tribunal declara en el caso "Catalíticos", o la concepción ilustrada de la Constitución, que en "Peña Wasaff" se representa como "un sistema orgánico y coherente de valores, principios y normas, todos los cuales guardan entre sí correspondencia $y$ armonía" ${ }^{42}$. Bien se sabe que la sabiduría del legislador, como también la racionalidad que conduce a la organicidad, a la coherencia y a la completud, hacen parte de los dogmas con que el iluminismo construyó una verdadera mitología en torno al Derecho ${ }^{43}$. En el plano específicamente constitucional, no deja de llamar la atención que, junto con la construcción de esta nueva forma de concebir a la Constitución, el Derecho y su interpretación, se hayan recreado valores propios de un nacionalismo que no se condice mucho con los predicados universalistas y globalizantes de las versiones latinoamericanas más conocidas del discurso neoconstitucio$\mathrm{nal}^{14}$. Si se compara la "adelantada" jurisprudencia de los casos "Isapres", "Píldora" o "Investigación de la paternidad", con los razonamientos sobre la soberanía que hace el Tribunal en la primera sentencia sobre la Corte Penal Internacional (en pleno siglo XXI) ${ }^{45}$, es posible advertir una notable diferencia de concepciones. Para explicarlo con una metáfora, puede decirse que el tribunal no se orienta en el tiempo con un solo reloj, sino con varios, y ajustados todos ellos a distintas horas.

Donde sí se advierte gran correspondencia entre la jurisprudencia y el fenómeno neoconstitucional es en el recurso a los valores como elemento vertebrador de las variantes examinadas en el párrafo precedente. Sin embargo, en este orden de cosas también es posible advertir contradicciones difíciles de resolver, que han sido señaladas con insistencia por la doctrina comparada y que ponen en duda, al menos en parte, lo que de verdaderamente liberal pueda tener lo neoconstitucional. Como sugiere

${ }^{41}$ STC rol No 325, de 26 de junio de 2001, consid. 11': "Que la Justicia Constitucional no puede resignarse frente a interpretaciones fáciles que conduzcan a estos resultados y es su deber esforzarse en buscar aquella otra que efectivamente demuestre que los numerales del artículo 82 que se examinan, tienen su razón de ser dentro de la preceptiva constitucional, sin forzar o contradecir los principios y valores que le sirven de sustento. Seguir este camino concuerda, además, con la sabiduría que debemos atribuir al Poder Constituyente, sea originario o derivado, en beneficio de la certeza jurídica". Este párrafo se repite en la STC rol No 591, de 11 de enero de 2007, consid. $5^{\circ}$.

${ }^{42}$ SS.TC rol No 976 , de 26 de junio de 2008 , consid. $34^{\circ}$; No 1218 , de 7 de julio de 2009 , consid. $35^{\circ}$; y 1287 , de 8 de septiembre de 2009 , consid. $66^{\circ}$.

${ }^{43}$ Grossi, Paolo, Mitologie giuridiche della modernità (Milano, Giuffrè, 2007), pp. 43 ss.

${ }^{44}$ Véase en este sentido, con valor paradigmático, la STC rol No 46, de 21 de diciembre de 1987.

${ }^{45}$ STC rol No 346, de 8 de abril de 2002. 
Pereira Menaut ${ }^{46}$, la visión de los derechos en tanto valores ofrece alguna dimensión problemática en el terreno filosófico y, lo que importa aquí, en el campo de la función jurisdiccional. En efecto, por una parte, la teoría de los valores va asociada a la ponderación como forma de argumentación, método popular y, al mismo tiempo, preñado de dificultades ${ }^{47}$. Por otra parte, en el plano ético-jurídico esta concepción permite la universalización de postulados (como los de la ética de Scheler o Hartmann) que, aplicados en sede judicial, no sólo hurtan del escrutinio público y de las partes las preferencias o puntos de vista particulares del juzgador (principal objeto de la crítica metodológica de Müller y otros) sino que además permiten que, por una vía extrajurídica, se reste contenido a la autonomía individual. Por eso Schmitt decía: "si algo tiene valor y cuánto, si algo es valor y en qué grado se puede determinar solamente desde un supuesto punto de vista o criterio particular" ${ }^{\prime \prime 8}$.

En esta posición de contradicción se encuentran los mismos valores cuya existencia predica el Tribunal Constitucional. Así por ejemplo, para el fallo dictado en el caso "Isapres" (y sus sentencias hermanas) una facultad otorgada por la ley, en este caso a un particular, debe entenderse "siempre" limitada por los valores, principios y normas constitucionales ${ }^{49}$. Si la limitación ha de entenderse respecto de los primeros, imprecisos por naturaleza, la primera víctima de esta forma de argumentar la sentencia será otro valor que también ha sido declarado como tal por el Tribunal Constitucional: la certeza jurídica ${ }^{50}$. Y junto con el sacrificio de la certeza, también caerá la predictibilidad de las decisiones judiciales.

El recurso a los valores omnipresentes en prácticamente todas las disputas constitucionales diluye también las fronteras entre las atribuciones de los jueces constitucionales y las del legislador. Esto queda en evidencia si se examina la doctrina de la deferencia hacia el legislador. En diversas sentencias el Tribunal se refiere a la inexistencia de una competencia

${ }^{46}$ Pereira Menaut, Carlos, Constitución, principios y valores, en Dereito. Revista Xuridica da Universidade de Santiago de Compostela, 13 (2004) 1, pp. 189-216.

${ }^{47}$ Aldunate, Eduardo, Derechos fundamentales (Santiago de Chile, LegalPublishing, 2008), pp. 273 ss.

${ }^{48}$ Schmitt, Carl, La tirania de los valores (traducción de A. Schmitt), en Estudios Políticos, 115 (1961), p. 71

${ }^{49}$ STC rol No 976, de 26 de junio de 2008, consid. 57: "[T] oda facultad que por ley se otorgue a las Isapres de fijar libre o discrecionalmente un factor para incorporarlo a dichas contrataciones debe suponerse siempre limitada por los valores, principios y disposiciones constitucionales, deducción lógica que, si fuera desconocida o ignorada, sería equivalente a quebrantar el valor de la supremacía que singulariza a la Constitución".

${ }^{50}$ SS. TC roles No 46, de 21 de diciembre de 1987, consid. 19% № 207, de 10 de febrero de 1995 , consid. $67^{\circ}$; y No 370 , de 9 de abril de 2003 , consid. $13^{\circ}$. 
para revisar el mérito o la bondad de las decisiones de la autoridad: "[e] $l$ Tribunal no legisla ni administra, ni entra a calificar la bondad de las disposiciones legales o administrativas. Sólo debe resolver si se ajustan o no a las normas, valores y principios constitucionales" ${ }^{2}$. Los valores, así de vagamente entendidos, hacen muy difícil identificar esos límites, por no decir que en sí mismos representan una forma de juzgar la "bondad constitucional" de las decisiones de la autoridad legislativa y administrativa.

Como se recordaba más arriba, una de las críticas al recurso a los valores dentro de la argumentación constitucional sostiene que dicho procedimiento supone algún riesgo para la libertad individual. Luego, a partir de la pregunta que encabeza este párrafo, puede decirse que lo neoconstitucional no siempre es coherente con lo constitucional, al menos sobre la base de un contenido mínimo liberal que se pueda atribuir a este último término. En efecto, según lo ha sugerido parte influyente de la doctrina alemana "si se dota a los postulados ético-morales o a los valores materiales de una vinculatividad jurídica que va más allá de la garantía de la libertad igual de todos y de las exigencias fundamentales de una vida en común ordenada, se llega inevitablemente a una socialización de la libertad y de la autonomía individuales. Estas quedan sometidas al dominio de los que ejercen el monopolio de la interpretación de estos postulados o valores, o que se lo apropian" 52 . Esta curiosa socialización se hace evidente con la representación que el Tribunal Constitucional hace del "proyecto máximo" o del "supremo objetivo" de la comunidad nacional (fórmulas que recuerdan más a una ideología que a una filosofía $)^{53}$. Entendidos en este clave, los valores evitan la "unilateralización" de la Constitución (según la expresión que utilizara recientemente nuestro Tribunal $)^{54}$ al precio de difuminar la claridad que deben tener los límites de la libertad. Se esconde

${ }^{51}$ La cita sigue: "[d] e una parte, debe velar por que la ley o el decreto no vulneren los limites constitucionales $y$, de otra, no puede inmiscuirse en la esencia del ejercicio de las funciones públicas que le corresponden al Congreso Nacional, al Presidente de la República o a los Tribunales de Justicia" [STC rol No 821, de 1 de abril de 2008 consid. $16^{\circ}$ ]. En sentido similar, SS.TC roles No 664, de 30 de mayo de 2007 , consid. $22^{\circ}$; No 1361, de 13 de mayo de 2009; y No 1295, de 6 de octubre de 2009, consid. $30^{\circ}$.

${ }^{52}$ BöCKEnFörde, Ernst, Estudios sobre el Estado de Derecho y la Democracia (traducción de R. Agapito, Barcelona, Trotta, 2000), pp. 42-43.

${ }^{53} \mathrm{La}$ inserción de la frase atribuida a W. Dilthey no deja de ser curiosa pues en la obra que sirve de fuente al Tribunal, y que fue escrita por uno de los ministros suscriptores del fallo, se advierten con mucha honestidad "los riesgos de equivocación" y el deseo de no plantear las ideas en un "tono categórico": CEA, José Luis, Derecho constitucional chileno (Santiago de Chile, Ediciones Pontificia Universidad Católica de Chile, 2002), I, pp. 154-155.

${ }^{54}$ STC rol No 1328 , de 6 de agosto de 2009 , consid. $20^{\circ}$. 
así, tras este artilugio, una curiosa paradoja del fenómeno neoconstitucional, donde lo "neo" o lo "nuevo" tiende a suprimir lo que de liberal pudo tener el adjetivo "constitucional".

Las proyecciones de la crítica antes descrita se aprecia bien en el fallo Isapres, que extiende a los "gobernados", es decir a los particulares, la sujeción a los principios y valores encarnados en las disposiciones constitucionales. Como se explica a continuación, se trata de una sentencia que, a través de un anecdótico trasvasije de frases sacadas de contexto, transforma completamente el sentido atribuido a la fuerza normativa de los valores hacia fines de la década de los ochenta.

En "Isapres" el Tribunal toma como si fuese doctrina lo dicho por él mismo dos décadas antes en el fallo "Almeyda" (STC rol No 46, 21 de diciembre de 1987). Defendiendo lo que "la doctrina ha afirmado", el Tribunal hace propio un considerando completo del fallo "Almeyda" (tomado de un estudio publicado por el ex Ministro del Tribunal, don Eugenio Valenzuela Somarriva, Valenzuela 2006, pp. 18-19) y transforma su sentido pasivo primario en una obligación de actuación. En efecto, en su contexto original (vinculado a las infracciones al antiguo artículo $8^{\circ} \mathrm{C}$.Pol.), la obediencia a los valores constitucionales se entendió en un sentido pasivo, con el sólo objeto de discernir si el antiguo artículo 8 podía ser aplicado retroactivamente. En otras palabras, el discurso de los valores se explicaba en la necesidad de encontrar un modo de aplicar el mentado artículo (y, por tanto, de ejercer la potestad del Tribunal) que no contradijese los derechos de las personas. En definitiva, la interpretación axiológica nacía para ordenar el ejercicio de las competencias públicas y no para ampliarlas.

En "Isapres", en cambio, la misma frase ("[e] stos preceptos no son meramente declarativos sino que constituyen disposiciones expresas que obligan a gobernantes y gobernados tanto en si mismas, como también en cuanto normas rectoras y vitales que coadyuvan a desentrañar el verdadero sentido y espíritu de la Constitución") ${ }^{55}$ adquiere un nuevo sentido, en la versión más fuerte de lo neoconstitucional. En "Isapres" el recurso a los valores irá dirigido a limitar la libertad contractual y, en último término, a trasladar la obligación de eficacia de los derechos sociales a las personas privadas. Como se sostiene en un agudo comentario de este fallo, "[c]on ello llega a plantear una idea de libertad contractual que no es más libertad, sino que se encuentra limitada por su función al servicio de la satisfacción de los derechos constitucionales de la contraparte" ${ }^{56}$.

${ }^{55}$ STC rol No 976 , de 26 de junio de 2008, consid. $31^{\circ}$.

${ }^{56}$ AldunATE, Eduardo, Jurisprudencia constitucional 2006-2008. Estudio selectivo (Santiago de Chile, LegalPublishing, 2009). 
Al igual que en Isapres, los fallos "Valdés Correa" y "Ominami Pascual" sobre la aplicación del artículo $2331 \mathrm{CC}$. insisten en la misma idea: la Constitución es también un depósito de valores y, puesto que ella es obligatoria, los valores constitucionales también dirigen la actuación de los particulares ${ }^{57}$. Y tal como acontece en el primero de estos fallos, la afirmación de la expansión o "irradiación" de dichos valores va más allá de la mera retórica, alcanzando o la libertad individual o la soberanía del pueblo expresada en el parlamento, que dicho sea de paso, puede ser otro "valor fundamental" ${ }^{8}$ del régimen republicano.

\section{CONSIDERACIONES FINALES Y CONCLUSIONES}

La teoría constitucional no siempre suele tener presente que el Derecho, los derechos y hasta los mismos valores son expresión de un lenguaje y este de una experiencia. Y como casi todos los lenguajes, estos son parciales representaciones de la realidad, de los modos de concebirla y de la experiencia de vivirla. En este sentido, la construcción de un derecho constitucional como si fuese un sistema de valores tiende a universalizar lo jurídico como si este campo perteneciese al plano de la ética y como si no fuese posible la función desde otra perspectiva. Este modo de ver las cosas, e incluso de considerar la dignidad como el "valor supremo" 59 o la "base esencial y primigenia" ${ }^{60}$, es muy propio de las sociedades que han experimentado traumas profundos en su historia constitucional. Como lo han explicado entre otros Herdegen ${ }^{61}$, Barnert y Doll ${ }^{62}$, parte de las respuestas que la jurisprudencia alemana ha dado al problema de los derechos fundamentales se deben a un razonable intento de arreglar cuentas con el pasado. Este modelo de constituciones, basadas en la dignidad y los valores $^{63}$, suelen presentar fricciones con la libertad, del mismo modo en

${ }^{57}$ SS.TC roles No 943 , de 10 de junio de 2008, consid. $31^{\circ}$; y No 1185 , de 16 de abril de 2009 , consid. $12^{\circ}$.

${ }^{58}$ STC rol No 740, de 18 de abril de 2008, voto disidente del Ministro Colombo, apdo. $31^{\circ}$

${ }^{59}$ STC rol No 1340 , de 29 de septiembre de 2009 , consid. $20^{\circ}$.

${ }^{60}$ STC rol No 591, de 11 de enero de 2007, consid. $3^{\circ}$.

${ }^{61}$ Herdegen, Matthias, Natural Law, Constitutional Values and Human Rights, en Human Rights Law Journal, 19 (1998) 2-4, pp. 37-42.

${ }^{62}$ Barnert, Elena - Doll, Natascha (), The Persisting Riddle of Fundamental Rights and the Role of the Constitutional Court in a Democratic State, en German Law Journal, 4 (2003) 3, párr. B, en <www.germanlawjournal.com>.

${ }^{63}$ Kommers, Donald, Can German Constitutionalism Serve as a Model for the United States?, en Zeitschrift für Auslandisches Öffentliches Recht und Völkerrecht, 58 (1998), pp. 787-798. 
que quizá las constituciones centradas en la libertad, para seguir el binomio de Kommers, presenten problemas con la dignidad.

De lo dicho hasta aquí es posible concluir:

a) La jurisprudencia del Tribunal Constitucional, especialmente a partir del único fallo del primer período que ha sido utilizado posteriormente por el propio Tribunal, se forma de manera prácticamente simultánea a la recepción del discurso sobre los valores constitucionales. El neoconstitucionalismo, luego, es un fenómeno que comienza a hacerse evidente en las postrimerías de la Constitución de 1925.

b) El discurso de los valores, evidencia fundamental del fenómeno neoconstitucional, no tarda mucho en reincorporarse al vocabulario del Tribunal Constitucional después de que este órgano es restablecido con la Constitución de 1980. En su primera aparición, como criterio orientador de la interpretación constitucional, el recurso a los valores sirve para contener el ejercicio de las potestades del Tribunal a partir de una norma que le concedía la capacidad de sancionar ciertos atentados graves al orden institucional (antiguo artículo 8 C.Pol.).

c) El examen del modo en que el Tribunal Constitucional recurre a los valores permite demostrar diversas contradicciones, sea entre valores o entre éstos y los principios de libertad y democracia.

d) En diversas sentencias dictadas bajo el período democrático de la Constitución de 1980 el discurso de los valores se extiende para justificar limitaciones a la autonomía del Parlamento y, particularmente, a la libertad individual. Lo uno y lo otro representa un episodio crítico para el ideal de un estado democrático y liberal. Esto último significa que el adjetivo neoconstitucional no siempre es coherente con lo constitucional.

[Recibido el 1 y aprobado el 27 de abril de 2010].

\section{BiBLIOGRAFÍA}

Aldunate, Eduardo, Derechos fundamentales (Santiago de Chile, LegalPublishing, 2008).

Aldunate, Eduardo, Jurisprudencia constitucional 2006-2008. Estudio selectivo (Santiago de Chile, LegalPublishing, 2009).

AmunÁtegui, Gabriel, Principios generales del Derecho constitucional (Santiago de Chile, Editorial Jurídica de Chile, 1953).

Barnert, Elena - Doll, Natascha, The Persisting Riddle of Fundamental Rights and the Role of the Constitutional Court in a Democratic State, en German Law Journal, 4 (2003) 3 [www.germanlawjournal.com].

BÖCKENFÖRDE, Ernst, Estudios sobre el Estado de Derecho y la Democracia (traducción de R. Agapito, Barcelona, Trotta, 2000). 
CARbonell, Miguel, El neoconstitucionalismo en su laberinto, en El MISMo (coordinador), Teoría del neoconstitucionalismo. Ensayos escogidos (Madrid, Trotta, 2007).

CeA, José Luis, Derecho constitucional chileno (Santiago de Chile, Ediciones Pontificia Universidad Católica de Chile, 2002), I.

CEA, José Luis, Escritos de justicia constitucional, en Cuadernos del Tribunal Constitucional, 35 (Santiago de Chile, 2007).

CEA, José Luis, La interpretación axiológica de la Constitución, en VV. AA., Interpretación, integración y razonamiento jurídicos (Santiago de Chile, Editorial Jurídica de Chile, 1992).

Comanducci, Paolo, Formas de (neo)constitucionalismo: un análisis metateórico, en Carbonell, Miguel (editor) Neoconstitucionalismo(s) (Madrid, Trotta, 2003).

Durán, Augusto, En torno al neoconstitucionalismo, en ArANCIBIA, Jaime - MARTÍNEZ, José Ignacio (coordinadores), La primacía de la persona. Estudios en homenaje al Profesor Eduardo Soto Kloss (Santiago de Chile, Legalpublishing Abeledo Perrot, 2009).

GiLl, Stephen, The Constitution of Global Capitalism, en http://www.theglobalsite. ac.uk/press/010gill.pdf [fecha de consulta: 3 de enero de 2010].

Grossi, Paolo, Mitologie giuridiche della modernità (Milano, Giuffrè, 2007).

Herdegen, Matthias, Natural Law, Constitutional Values and Human Rights, en Human Rights Law Journal, 19 (1998) 2-4.

Кокотт, Juliane, From Reception and Transplantation to Convergence of Constitutionals Models in the Age of Globalisation with Special Reference to the German Basic Law, en STARcK, C. (editor), Constitutionalism, Universalism and Democracy. A Comparative Analysis (Baden Baden, Nomos, 1999).

Kommers, Donald, Can German Constitutionalism Serve as a Model for the United States? en Zeitschrift für Auslandisches Öffentliches Recht und Völkerrecht, 58 (1998).

MEZA ZúNIGa, Cristina, El recurso a los valores en la jurisprudencia del Tribunal Constitucional chileno (1970-2006) (Memoria de Licenciatura, Prof. guía M. Núñez P., Facultad de Ciencias Jurídicas de la Universidad de Antofagasta, Antofagasta, 2010).

Nogueira, Humberto, Lineamientos de interpretación constitucional (Santiago de Chile, Librotecnia, 2006).

NúNÉE, Manuel, Una introducción al constitucionalismo postmoderno y al pluralismo constitucional, en Revista Chilena de Derecho, 31 (2004) 1.

PARejo, Luciano, Constitución y valores del ordenamiento (Madrid, Centro de Estudios Ramón Areces, 1990).

Parejo, Luciano, Valores supremos, en Enciclopedia Jurídica Básica (Madrid, Civitas, 1995), IV,

Pereira Menaut, Carlos, Constitución, principios y valores, en Dereito. Revista Xuridica da Universidade de Santiago de Compostela, 13 (2004) 1.

Pérez Muñoz, Fernanda, El recurso a los valores en la jurisprudencia del Tribunal Constitucional chileno (2006-2009) (Memoria de Licenciatura, Prof. guía M. Núñez P., Escuela de Derecho de la Universidad Católica del Norte, Antofagasta, 2010).

Pernice, Ingolf, Multilevel Constitutionalism in the European Union, en European Law Review, 27 (2002).

Pozzolo, Susana, Neocostituzionalismo: breve nota sulla fortuna di una parola, en Materiali per una storia della cultura giuridica, 38 (2008) 2. 
RugGeri, Antonio, 'Balances' entre los valores constitucionales y teoría de las fuentes, en Teoria y Realidad Constitucional 12-13 (2004).

Schiavello, Aldo, Neocostituzionalismo o neocostituzionalismi, en Diritto e questione pubbliche, 3 (2003).

Schmitt, Carl, La tiranía de los valores (traducción de A. Schmitt), en Estudios Políticos, 115 (1961).

SHAW, Jo, Postnational Constitutionalism in the European Union, en Journal of European Public Policy, 6 (1999) 4.

SMEND, Rudolf, Constitución y Derecho Constitucional (traducción de J. M. Beneyto, Madrid, Centro de Estudios Constitucionales, 1985).

Valenzuela, Eugenio, Criterios de hermenéutica constitucional aplicados por el Tribunal Constitucional. Contribución del Tribunal a la institucionalización democrática, en Cuadernos del Tribunal Constitucional, 31 (Santiago de Chile, 2006).

Verdugo, Mario - García, Ana María, Manual de Derecho politico. Instituciones políticas (Santiago de Chile, Editorial Jurídica de Chile, 1996).

Vivanco, Angela, Curso de Derecho constitucional. Bases conceptuales y doctrinarias del Derecho constitucional (Santiago de Chile, Ediciones Pontificia Universidad Católica de Chile, 2001), I.

WalKer, Neil, Flexibility within a Metaconstitutional Frame: Reflections of the future of Legal Authority in Europe, en Jean Monnet Working Paper, 12 (1999).

Walker, Neil, The Idea of Constitutional Pluralism, en Modern Law Review, 65 (2002).

WeIler, Joseph, European Neo-constitutionalism: in Search of Foundations for the European Constitutional Order, en Bellamy - Castiglione (editores) Constitutionalism in Transformation: European and Theoretical Perspectives (Oxford, Blackwell, 1996). 
